\title{
Physiologic Lightening
}

National Cancer Institute

\section{Source}

National Cancer Institute. Physiologic Lightening. NCI Thesaurus. Code C92844.

A physical feeling of being able to breathe better during late trimester of pregnancy when the baby starts to descend lower into the pelvic cavity. 